\title{
Histiocitoma fibroso do saco lacrimal: Relato de um caso
}

\author{
Lacrimal sac fibrous histiocy toma:Case report
}

\author{
Carolina Lemos Curi ${ }^{1}$ \\ Everaldo Lemos ${ }^{2}$ \\ Eduardo Pereira de Macedo $^{3}$ \\ Virgínia Bohrer Costa ${ }^{4}$
}

\section{RESUMO}

Os autores descrevem um caso raro de histiocitoma fibroso acometendo o saco lacrimal. A paciente apresentava quadro clínico que simulava dacriocistite crônica, com dacriocistografia sugestiva de obstrução alta das vias lacrimais. A completa remoção cirúrgica do tumor e posterior dacriocistorrinostomia foram fundamentais no diagnósticoe controle da doença. Descritores: Histiocitoma fibroso; Aparelho lacrimal

\section{INTRODUÇ̃̃O}

As neoplasias do saco lacrimal são raras. Vários tumores podem acometer o saco lacrimal entre eles o histiocitoma fibrocítico ; tumor de origem mesenquimal cujas manifestações oculares geralmente envolvem a órbita ou menos comumente conjuntiva, corpo ciliar e limbo. O acometimento do saco lacrimal por esse tumor é extremamente raro, sendo descritos menos de 20 casos na literatura. O objetivo deste relato é descrever um caso de histiocitoma fibrocítico de saco lacrimal.

\section{RELATO DE CASO}

Paciente de 82 anos do sexo feminino, foi encaminhada para exame oftalmológico devido à irritação crônica em ambos os olhos e lacrimejamento. Relatava ainda o aparecimento de tumoração no canto interno do olho esquerdo. Ao exame externo apresentava triquíase no terço médio da pálpebra inferior de ambos os olhos e uma massa endurecida, bem delimitada e imóvel na região do saco lacrimal esquerdo. A acuidade visual era de 20/40 devido à catarata córtico-nuclear bilateral. $\mathrm{O}$ segmento posterior apresentava-se sem alterações e a pressão intra-ocular estava dentro dos padrões de normalidade. Foi realizada uma dacriocistografia que demonstrou ausência de enchimento do saco lacrimal, com o contraste preenchendo apenas os canalículos. Após uma semana a paciente retornou com sinais inflamatórios no local da tumoração simulando uma dacriocistite aguda. Diante do quadro obstrutivo, indicamos procedimento cirúrgico. Durante a exploração cirúrgica encontramos uma massa endurecida, arredondada, medindo cerca de $6 \mathrm{x}$ $6 \mathrm{~mm}$ na parede lateral do saco lacrimal esquerdo, bem delimitada, adjacente ao canalículo comum. Não havia sinal de invasão de estruturas adjacentes. A tumoração foi inteiramente ressecada e enviada para exame anátomopatológico que revelou uma lesão caracterizada por proliferação de fibroblastos, com citoplasmas alongados e núcleos fusiformes e vesiculados, ninhos de células histiocitárias com citoplasmas amplos e xantomatosos, raras células gigantes multinucleadas e focos de células inflamatórias linfocitárias. A imuno-histoquímica foi positiva para vimentina e CD 68. Revelou neoplasia benigna de origem mesenquimal constituída ora por células arredondadas com núcleo de cromatina densa, ocupando todo o 
volume celular, ora por células alongadas com núcleos exibindo cromatina frouxa. Não foi observada mitose, atipia nuclear ou áreas de hemorragia. Esses achados foram compatíveis com o diagnóstico de histiocitoma fibrocítico benigno do saco lacrimal.

\section{DISCUSSÃO}

As neoplasias do saco lacrimal são raras, podendo ter origem epitelial (59 a 75\% dos casos) ou não epitelial (27 a 41\% dos casos $)^{(1-2)}$. O quadro clínico é caracterizado por epífora, episódios recorrentes de dacriocistite e finalmente o aparecimento de uma massa na região do saco lacrimal. Pode haver ainda sangramento nasal, ou através do ponto lacrimal. O diagnóstico clínico é dificilmente realizado.

A dacriocistografia varia de acordo com a localização do tumor e geralmente mostra um defeito de enchimento ou um retardo no escoamento do contraste.

O histiocitoma fibrocítico é um tumor não epitelial de origem mesenquimal que raramente acomete o saco lacrimal. A maioria dos casos publicados na literatura oftalmológica são orbitários. Em 1978, foi descrito o primeiro caso comprovado de histiocitoma fibrocítico do saco lacrimal ${ }^{(3)}$. Posteriormente, Marback et al. relataram mais dois $\operatorname{casos}^{(4)}$; e, em um estudo clínico-patológico de 115 neoplasias de saco lacrimal, foram encontrados mais 13 histiocitomas ${ }^{(2)}$.

Os estudos mais recentes ${ }^{(5)}$ sugerem que esta neoplasia origina-se de uma célula mesenquimal primitiva, devido à grande variedade de tipos celulares encontrados histologicamente. É um tumor predominantemente celular, composto principalmente por fibroblastos, histiócitos, células xantomatosas, multinucleadas e células imaturas lembrando "steam cells", num padrão entrelaçado. A quantidade de cada uma delas e a quantidade de fibrose é muito variável, e durante algum tempo causou alguma confusão na nomenclatura desse tumor. Inicialmente se achava que os tumores histiocíticos podiam ser

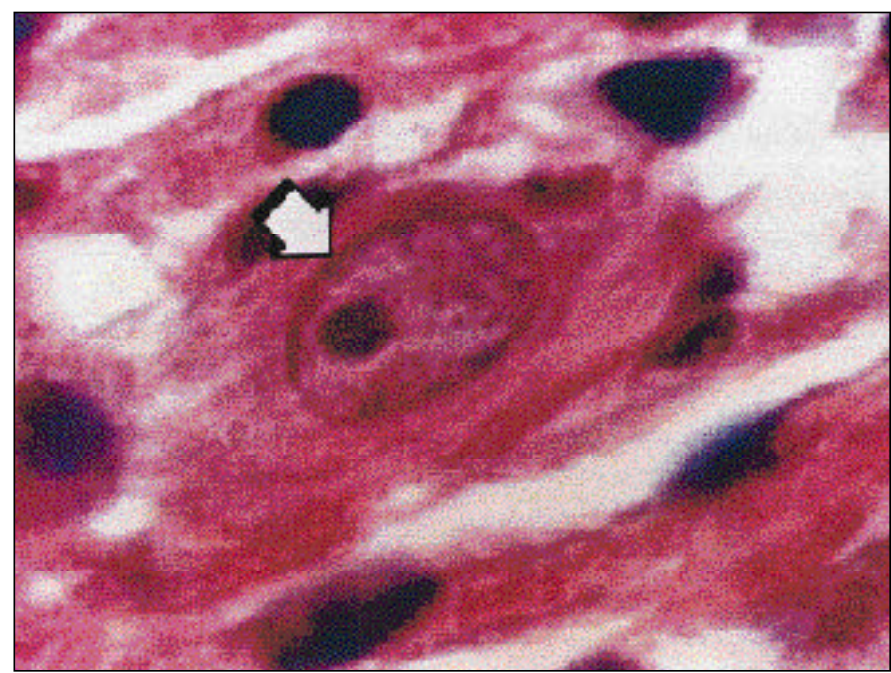

Figura 1 - Histiócito exibindo núcleo vesiculoso e nucléolo proeminente (seta)

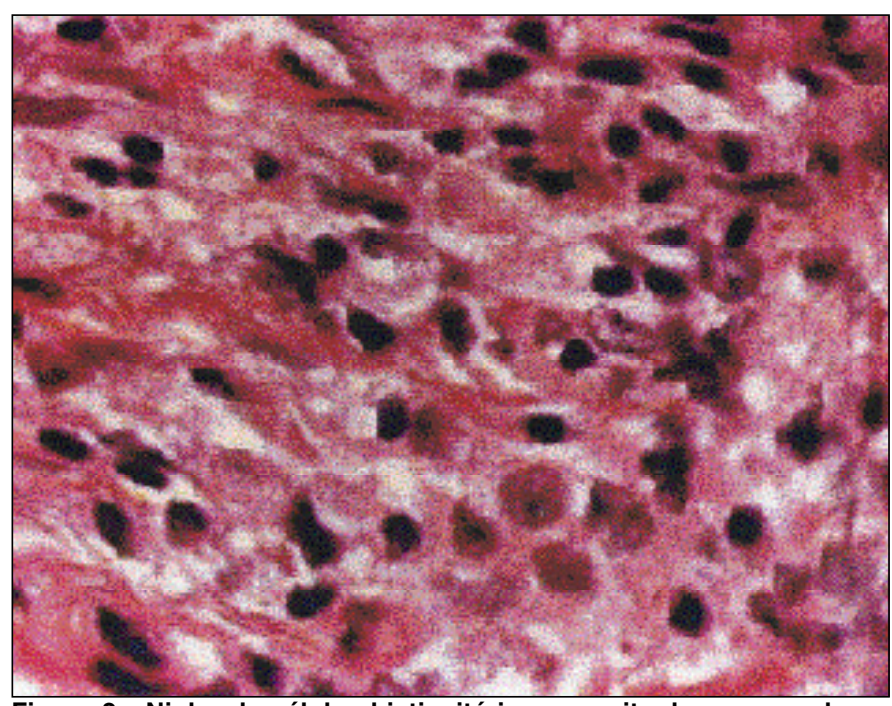

Figura 2 - Ninho de células histiocitárias com citoplasmas amplos e xantomatosos

divididos em dois tipos, um predominantemente celular (histiocitoma) e um predominantemente fibroso (inicialmente chamado fibroxantoma).

O histiocitoma fibrocítico geralmente tem um curso benigno, mas também pode ser localmente invasivo e raramente malignos. A malignidade está relacionada à presença de atividade mitótica e infiltração das margens do tumor. Lesões pequenas, superficiais e inflamadas, como era o caso da nossa paciente, representam a maioria dos casos e têm conotação benigna, podendo haver recorrência local.

Seu diagnóstico pode ser difícil devido aos variados achados morfológicos. O diagnóstico diferencial é feito clinicamente com dacriocistite crônica e histologicamente com outros tumores tais como hemangiopericitomas (principalmente histiocitomas fibrocíticos vascularizados), fibromatoses, tumores neurogênicos, e leiomiomas.

No nosso caso, a paciente vinha sendo tratada clinicamente como dacriocistite e nos chamou a atenção a consistência firme da massa na região do saco lacrimal. Depois de realizada a dacriocistografia, optamos por uma intervenção cirúrgica, devido ao caráter obstrutivo do caso. A cirurgia foi realizada em dois tempos, porque o tumor estava bem delimitado e foi facilmente ressecado na primeira cirurgia, mas a paciente continuou com o quadro de epífora, sendo submetida posteriormente a uma dacriocistorrinostomia, com bom resultado.

Apesar de raro o histiocitoma fibrocítico deve ser lembrado como diagnóstico diferencial em casos de dacriocistite crônica. A remoção cirúrgica do tumor parece ser a melhor opção diagnóstica e terapêutica nesses casos.

\section{AGRADECIMENTO}

À professora Vânia Glória Silami Lopes, do Departamento de Patologia da Universidade Federal Fluminense, pela realização da imuno-histoquímica do material colhido. 


\section{ABSTRACT}

The authors report an unusual case of fibrous histiocytoma of the lacrimal sac. The patient presented with clinical features of chronic dacryocystitis. Dacryocystogram disclosed a high level obstruction. Surgical management was fundamental to the diagnosis and control of the disease.

Keywords: Histiocytoma, fibrous; Lacrimal apparatus

\section{REFERÊNCIAS}

1. Pe'er JJ, Stefanyszyn M, Hidayat AA. Nonepithelial tumors of the lacrimal sac. Am J Ophthalmol. 1994;118:650-8.

2. Stefanyszyn MA, Hidayat AA, Pe'er JJ, Flanagan JC. Lacrimal sac tumors. Ophthal Plast Reconstr. Surg 1994;10:169-84.

3. Cole SH, Ferry AP, Fibrous histiocytoma (fibrous xhantoma) of the lacrimal sac. Arch. Ophthalmol. 1978;96:1647-9.

4. Marback RL, Kincaid MC, Green WR, Iliff WJ. Fibrous histiocytoma of the lacrimal sac. Am J Ophthalmol 1982;93:511-7.

5. Choi G, Lee U, Won NH. Fibrous histiocytoma of the lacrimal sac. Head Neck 1997;19:72-5. 